\title{
Supplementing fibroblast growth factor 2 during bovine oocyte in vitro maturation promotes subsequent embryonic development
}

\author{
Kun Zhang ${ }^{1}$, Alan D. Ealy ${ }^{2^{*}}$ \\ ${ }^{1}$ Department of Veterinary and Animal Sciences, University of Massachusetts at Amherst, Amherst, USA \\ ${ }^{2}$ Department of Animal Sciences, D. H. Barron Reproductive and Perinatal Biology Research Program, University of Florida, \\ Gainesville, USA; ${ }^{*}$ Corresponding Author: ealy@ufl.edu
}

Received 14 February 2012; revised 23 March 2012; accepted 30 March 2012

\begin{abstract}
The overall objective of this work was to describe whether supplementing fibroblast growth factor 2 (FGF2) during in vitro maturation (IVM) affects cumulus and oocyte maturation and subsequent embryonic development. Supplementing $0.5,5$ or $50 \mathrm{ng} / \mathrm{ml}$ FGF2 to cumulus-oocyte complexes (COCs) increased the percentage of oocytes with extruded polar bodies after IVM. Supplementing FGF2 during $\mathrm{COC}$ maturation did not affect in vitro fertilization (IVF) rates but increased the percentage of blastocysts at day 7 post-IVF. Blastocyst cell number was not affected by FGF2 treatment. Supplementation with FGF2 did not affect cumulus expansion but reduced the proportion of apoptotic cumulus cells after IVM. The relative abundance of several cumulus cell transcripts associated with apoptosis and cumulus cell activity were not altered by FGF2 treatment. In summary, improvements in blastocyst development were achieved by FGF2 treatment during oocyte maturation. The reason for the enhanced oocyte competency remains unclear but may occur because of improvements in oocyte maturation and cumulus cell viability during IVM.
\end{abstract}

Keywords: Cattle; Embryo Development; Blastocyst; FGF2; Folliculogenesis

\section{INTRODUCTION}

Several paracrine and autocrine factors are produced within the follicular niche control oocyte maturation [13]. Supplementing specific paracrine and endocrine components during in vitro maturation (IVM) of bovine cumulus-oocyte complexes (COCs) can improve the suc- cess of in vitro embryo production and maximize embryonic competency to generate healthy offspring after embryo transfer. Providing gonadotropins, namely FSH, is commonplace for maximizing $\mathrm{COC}$ maturation and fertilization [2,3]. Oocyte-secreted factors also improve oocyte competency. Supplementing growth differentiation factor 9 (GDF9) and/or bone morphogenetic protein 15 (BMP15) during IVM improved subsequent bovine embryo development [4], and supplementing GDF9 during IVM of mouse COCs improved embryo development and post-transfer survival [5]. Increased bovine embryo development rates were also observed after supplementation with fibroblast growth factor 10 (FGF10), a thecaderived factor $[6,7]$.

Several other FGFs are produced in oocytes and follicular somatic cells of cattle [6-10], pigs [11], mice [1214] and women $[15,16]$. Also, each of the four main classes of receptors that interact with FGFs (termed FGFR1-4) is present within oocytes and granulosa and cumulus cells [6]. FGFs are involved in various biological processes during folliculogenesis, including primordial follicle activation and regulation of granulosa and cumulus cell mitosis, apoptosis and glycolysis [12,17-19]. The role of these various FGFs during the final period of oocyte maturation remain largely unexplored.

An FGF of recent interest for a functional role during oocyte maturation is FGF2 (also known as basic FGF). It is produced by theca and granulosa cells, and its transcript abundance increased during periovulatory follicle growth and during bovine IVM [20-22]. Moreover, selective FGF2 single nucleotide polymorphisms (SNPs) are linked with IVP success rate in cattle [23]. We proposed that providing FGF2 during IVM would benefit oocyte maturation in ways that benefit subsequent embryo development.

\section{MATERIALS AND METHODS}

\subsection{Animal Assurances and Reagents}

All studies were completed in accordance with and 
with the approval of the Institutional Animal Care and Use Committee (IACUC) at the University of Florida. Unless stated otherwise reagents were purchased from Sigma-Aldrich Co. (St. Louis, MO, USA).

\subsection{Bovine in Vitro Maturation, Fertilization and Culture}

The in vitro production (IVP) of bovine embryos was accomplished as described previously [6,24,25]. Briefly, ovaries were obtained from Central Beef Packing Co. (CenterHill, FL, USA) and transported to the lab. Cumulus-oocyte complexes (COCs) were collected and groups of $10-12$ COCs were cultured in $50 \mu$ drops of oocyte maturation medium (TCM199 containing Earle's salts supplemented with $25 \mu \mathrm{g} / \mathrm{ml}$ bovine FSH [Bioniche Life Sciences, Belleville, Ontario, CA], $2 \mu \mathrm{g} /$ mlestradiol $17-\beta$, $22 \mu \mathrm{g} / \mathrm{ml}$ sodium pyruvate, $50 \mu \mathrm{g} / \mathrm{ml}$ gentamicin sulfate, $1 \mathrm{mM}$ glutamine). In most studies serum-free maturation medium was used and $1 \mathrm{mg} / \mathrm{ml}$ polyvinyl alcohol (PVA) was included as a protein substitute. In one study, maturation medium was supplemented with $10 \%[\mathrm{v} / \mathrm{v}]$ bovine steer serum (Pel-Freeze Biologicals, Rogers AR USA).

After $21 \mathrm{~h}$ at $38.5^{\circ} \mathrm{C}$ in $5 \% \mathrm{CO}_{2}$ in humidified air, COCs were transferred to fertilization medium and exposed to Percoll gradient-purified bovine spermatozoa. The same pool of semen from three bulls was used throughout the studies. After 8 to $10 \mathrm{~h}$ at $38.5^{\circ} \mathrm{C}\left(5 \% \mathrm{CO}_{2}\right.$ in humidified air), cumulus cells were removed by vortexing with $1000 \mathrm{U} / \mathrm{ml}$ hyaluronidase. Denuded zygotes were placed in groups of 25 - 30 in $50 \mu \mathrm{l}$ drops of modified synthetic oviduct medium (mSOF; Millipore Corp., Billerica, MA USA) [26]. Drops were covered with mineral oil and maintained at $38.5^{\circ} \mathrm{C}$ in $5 \% \mathrm{CO}_{2}, 5 \% \mathrm{O}_{2}$ and $90 \% \mathrm{~N}_{2}$ for 8 days.

\subsection{Oocyte Maturation}

Serum-free maturation medium was supplemented with 0 (vehicle only), $0.5,5$ or $50 \mathrm{ng} / \mathrm{ml}$ recombinant bovine FGF2 (R \& D Systems, Minneapolis, MN USA). Stocks of FGF2 were prepared in TCM199 containing Earle's salts (Invitrogen Corp.) and 1\% [w/v] bovine serum albumin (BSA). After 21 to $22 \mathrm{~h}$, COCs were vortexed for $4 \mathrm{~min}$ to remove cumulus cells. The proportion of oocytes that extruded their first polar body was determined by using stereomicroscopy. Seven replicate studies were completed, and each study contained from 10 to 22 COCs.

In a second study cumulus cells were removed from oocytes before IVM. For this, COCs were vortexed for 4 min and denuded oocytes were cultured in serum-free maturation medium for 21 to $22 \mathrm{~h}$ with 0 or $5 \mathrm{ng} / \mathrm{ml}$ FGF2. Four replicate studies were completed, and each study contained from 10 to 24 denuded oocytes.

\subsection{Embryonic Development}

Serum-free maturation medium was supplemented with $0,0.5,5$ or $50 \mathrm{ng} / \mathrm{ml} \mathrm{FGF2} \mathrm{immediately} \mathrm{before} \mathrm{be-}$ ginning IVM. After maturation, COCs were rinsed in PBS-PVA and were fertilized and cultured without supplemental FGF2. At day 3 post-IVF, the proportion of cleaved zygotes and embryos containing $\geq 8$ blastomeres was recorded. The proportion blastocysts and stage of blastocyst development (regular or advanced [expanded, hatching or hatched]) was recorded at days 7 and 8 postIVF. Four replicate studies were completed, and each study contained from 26 to 35 COCs.

Blastomere numbers were determined for blastocysts at day 8 post-IVF by fixing blastocysts with $4 \%[\mathrm{w} / \mathrm{v}]$ paraformaldehyde, permeabilizing with $0.1 \%[\mathrm{v} / \mathrm{v}]$ Triton X-100 and staining with $1 \mu \mathrm{g} / \mathrm{ml}$ Hoechst 33342 (Invitrogen Corp., Carlsbad, CA USA) [6]. Blastocysts were mounted on slides and the number of nuclei per blastocyst was counted by using epifluorescence microscopy (Nikon TE2000, Nikon Corp., Melville, NY USA) ( $\mathrm{n}=$ 26 to 34 blastocysts examined over 4 replicate studies).

One study used maturation medium containing serum. For this, either $0.5 \mathrm{ng} / \mathrm{ml} \mathrm{FGF2}$ or carrier-only was supplemented to maturation medium containing $10 \%$ bovine steer serum immediately before COC culture. The COCs were rinsed in PBS-PVA and fertilized and cultured without supplemental FGF2. Embryo development was examined at days 3, 7 and 8 and as described previously. Three replicate studies were completed, and each study contained from 25 to 34 COCs.

\subsection{Cumulus Cell Expansion}

Serum-free maturation medium was supplemented with $0,0.5,5$ or $50 \mathrm{ng} / \mathrm{ml} \mathrm{FGF2} \mathrm{immediately} \mathrm{before} \mathrm{IVM.}$ After 21 to $22 \mathrm{~h}$ of IVM, the degree of cumulus expansion in COCs were scored visually by phase-contrast microscopy on a 1 to 3 scale $(1$ = poor expansion characterized by few morphological changes compared with before maturation; 2 = partial expansion characterized by fair expansion but notable clusters lacking expansion; 3 $=$ complete or nearly complete expansion) $[6,27]$. Six replicate studies were completed, and each study contained from 22 to 35 COCs.

\subsection{Cumulus Cell Apoptosis}

Serum-free maturation medium was supplemented with $0,0.5$ or $5 \mathrm{ng} / \mathrm{ml} \mathrm{FGF2}$ immediately before COC culture. The percentage of TUNEL-positive cumulus cells were determined after 21 to $22 \mathrm{~h}$ of maturation by using FITCconjugated dUTP and $1 \mu \mathrm{g} / \mathrm{ml}$ Hoechst 33342 as a counterstain (Roche Applied Sciences, Indianapolis, IN USA). COCs were mounted on slides and analyzed with epif- 
luorescence microscopy. The proportion of TUNEL-positive cumulus cells was calculated by dividing the number of TUNEL-positive nuclei by total nuclei numbers for each COC. Four replicate studies were completed, and each study contained from 25 to 35 COCs.

\subsection{Selected Transcript Profiling in Cumulus Cells}

Serum-free maturation medium was supplemented with 0 or $5 \mathrm{ng} / \mathrm{ml}$ FGF2 immediately before COC culture. After $6 \mathrm{~h}$ of maturation or at the end of maturation (21 to $22 \mathrm{~h}$ ), cumulus cells and oocytes were separated from each other by repeat pipetting. Pools of cumulus cellsderived from 25 to 35 COCs were transferred to microcentrifuge tubes, centrifuged at $700 \times \mathrm{g}$ for $2 \mathrm{~min}$ at room temperature to remove residual solution, snap-frozen in liquid nitrogen and stored at $-80^{\circ} \mathrm{C}$. Total cellular (tc) RNA was extracted using the RNeasy Micro Kit (Qiagen, Valencia, CA USA). RNA concentrations and integrity $\left(\mathrm{A}_{260} / \mathrm{A}_{280}\right.$ ratio $\left.\geq 1.8\right)$ was determined using a NanoDrop 2000 Spectrophotometer (Thermo Scientific, Wilmington, DE, USA). Each tcRNAsample (10 ng/reaction) was incubated in RNase-free DNase (New England Biolabs, Ipswich, MA USA) and reverse transcribed using the High Capacity cDNA Reverse Transcription Kit (Applied Biosystems, Foster City, CA USA). One study examined a series of transcripts associated with apoptosis (BCL2, BAX, BAD, XIAP, FAS) [28,29] (n=4 replicate studies). Another study examined several cumulus cell transcripts associated with oocyte and embryo competency (CTSB, EFGR, SPRY2, FSHR, HAS2) [6,3032] ( $\mathrm{n}=3$ replicate studies). Primers (Invitrogen Corp.) were used at a concentration of 200 nMand were mixed with RT products and SYBR Green PCR Master Mix. After an initial activation/denaturation step $\left(50^{\circ} \mathrm{C}\right.$ for 2 $\min , 95^{\circ} \mathrm{C}$ for $10 \mathrm{~min}$ ), 40 cycles of a 2-step amplification protocol $\left(60^{\circ} \mathrm{C}\right.$ for $1 \mathrm{~min}, 95^{\circ} \mathrm{C}$ for $\left.15 \mathrm{sec}\right)$ were completed using a 7300 Real-Time PCR System (Applied Biosystems). A dissociation curve analysis $\left(60^{\circ} \mathrm{C}\right.$ to $95^{\circ} \mathrm{C}$ ) was used to verify the amplification of a single product.Each sample was run in triplicate and a fourth reaction lacking exposure to reverse transcriptase was included to verify the absence of genomic contamination. Relative amounts of $18 S$ RNA were used as an internal control for quantifying relative gene expression. Abundance of $18 S$ RNA did not change based on treatment. The ratio of target to reference RNA was used to determine relative expression $\left(2^{-\mathrm{CT}[\text { target }]} / 2^{-\mathrm{CT}[\text { reference }]}\right)$ [6].

\subsection{Statistical Analyses}

All analyses were completed with least-squares analysis of variance (LS-ANOVA) using the general linear model (GLM) of the Statistical Analysis System [33]. All percentage data were arcsine-transformed before analysis. Percentage data are presented as non-transformed values and SEMs. Orthogonal contrasts were completed on FGF2 dose-response studies (control vs. all FGF2 treatments; 0.5 vs. $5 \mathrm{ng} / \mathrm{ml} \mathrm{FGF2;} 0.5$ and 5 vs. $50 \mathrm{ng} / \mathrm{ml} \mathrm{FGF2).} \mathrm{COC}$ expansion was analyzed by examining the mean COC expansion index (calculated for each treatment within each replicate) and by examining the proportion of COCs observed within each of the non-parametric rankings (1, 2 and 3 ). The ratio of target to reference RNA was used to analyze qRT-PCR data.

\section{RESULTS}

\subsection{FGF2 Supplementation Affects Oocyte Maturation}

Providing FGF2 affected first polar body extrusion (Figure 1). Specifically, an increase in the percentage of oocytes with an extruded polar body was detected when comparing controls with COCs incubated with $0.5,5$ or $50 \mathrm{ng} / \mathrm{ml} \mathrm{FGF2}$ (Orthogonal contrast of control vs. all FGF2 treatments; $\mathrm{P}=0.05)$. No differences in polar body extrusion rates were detected between FGF2 treatments.

\subsection{FGF2 Supplementation during IVM Impacts Subsequent Embryo Development}

Several studies were completed to examine whether fertilization success and subsequent embryo development

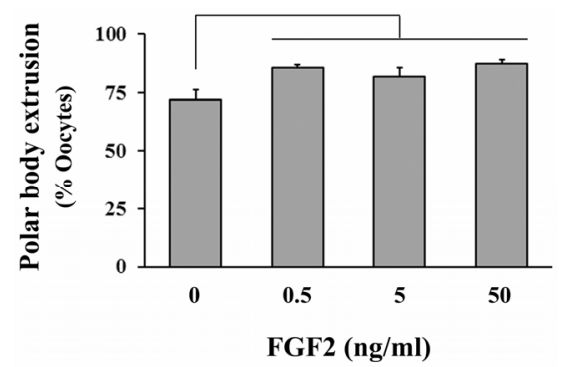

Figure 1. The effect of FGF2 supplementation during IVM on oocyte maturation. COCs ( $\mathrm{n}=10-22 /$ replicate; 7 replicate studies) were cultured in maturation medium containing FSH and $0,0.5,5$ or $50 \mathrm{ng} / \mathrm{ml}$ FGF2. After $21 \mathrm{~h}$, cumulus cells were removed by vortexing and the percentage of oocytes that extruded their first polar body (Panel A) and achieved MII (Panel B) was determined. In Panel A, a significant difference between controls and all FGF2 treatment groups were detected by using Orthogonal contrasts $(\mathrm{P}=0.05)$. In Panel B, percentage of oocytes that reached MII differed between the control and oocytes exposed to $5 \mathrm{ng} / \mathrm{ml} \mathrm{FGF2}$. The other FGF2 treatments did not differ from the control. 
rates were altered after COC supplementation with FGF2 $(0,0.5 .5,50 \mathrm{ng} / \mathrm{ml})$. In the first study, COCs were matured in medium lacking serum (replaced with $1 \mathrm{mg} / \mathrm{ml}$ PVA). As shown in Table 1, FGF2 supplementation during IVM did not affect the percentage of presumptive zygotes that cleaved at day 3 after IVF and the percentage of embryos containing $\geq 8$ cells at day 3 . Exposure to FGF2 during IVM increased the percentage of cleaved embryos that became blastocysts at day $7(\mathrm{P}=0.02)$. A tendency for an increase in blastocyst formation at day 7 was observed when data were examined based on the percentage of oocytes that became blastocysts at day 7 (P $=0.07$ ). No effects of FGF2 supplementation were detected at day 8 on blastocyst and advanced blastocyst rates and total blastomere number.

Since most bovine IVP systems utilize bovine steer serum in maturation medium to maximize fertilization and subsequent embryonic development potential [24,25], a study was completed to determine if beneficial effects of FGF2 could be detected when using serum-containing maturation medium. Supplementing $0.5 \mathrm{ng} / \mathrm{ml} \mathrm{FGF2} \mathrm{to}$ maturation medium containing serum did not affect the percentage of cleaved embryos or the percentage of embryos containing $\geq 8$ cells at day 3 post-IVF (data not shown) but increased ( $\mathrm{P}=0.05)$ the percentage of cleaved embryos that became blastocysts at day 7 post-IVF ( $41 \%$ $\pm 3 \%$ vs. $28 \% \pm 5 \%$ for FGF2-treated vs. control). A nonsignificant trend also was observed when data was analyzed based on the percentage of oocytes that became blastocysts at day $7(26 \% \pm 5 \%$ vs. $17 \% \pm 4 \%$ for FGF2treated vs. control; $\mathrm{P}=0.14$ ). Blastocyst development at day 8 was not affected by FGF2 treatment (data not shown).

\subsection{Potential Role of Cumulus Cells in Mediating FGF2 Effects}

Changes in cumulus cell morphology, viability, and gene expression were examined in COCs examine whether FGF2 may be acting through cumulus cells to promote oocyte maturation and improve embryo development.

Cumulus expansion rates were not altered by FGF2 supplementation. Neither mean cumulus expansion score nor the proportion of COCs within each expansion category was altered by supplementation with $0.5,5$ or 50 ng/ml FGF2 (overall averages across all treatments: 9\% category $1,67 \%$ category $2,24 \%$ category 3 ; mean index average $=2.1$ ).

The necessity of cumulus cells for mediating FGF2 effects on oocyte maturation was examined by removing cumulus cells before IVM and culturing denuded oocytes in maturation medium containing 0 or $5 \mathrm{ng} / \mathrm{ml} \mathrm{FGF2.}$ Supplementation with FGF2 had not effect on the percentage of denuded oocytes extruding their first polar body $(71 \% \pm 9 \%$ vs. $56 \% \pm 8 \%$ for 0 vs. $5 \mathrm{ng} / \mathrm{ml} \mathrm{FGF} 2$, respectively). Effects of denuded oocyte culture on subsequent fertilization and embryo development were not examined.

Changes in the percentage of TUNEL-positive (i.e. apoptotic) cumulus cells were observed in COCs exposed to FGF2 treatment (Figure 2). Supplementation with either 0.5 or $5 \mathrm{ng} / \mathrm{ml} \mathrm{FGF} 2$ decreased $(\mathrm{P}=0.03)$ the percentage of TUNEL-positive cumulus cell nuclei at the end of the maturation period when compared with the control.

To follow up on this observation, the influence of FGF2 supplementation on expression profiles of several

Table 1. The effect of supplementing FGF2 during COC maturation on subsequent in vitro development.

\begin{tabular}{|c|c|c|c|c|c|}
\hline \multirow{2}{*}{ Parameter $^{1}$} & \multicolumn{4}{|c|}{ FGF2 (ng/ml) } & \multirow[t]{2}{*}{ P Value $^{2}$} \\
\hline & 0 & 0.5 & 5 & 50 & \\
\hline \multicolumn{6}{|l|}{ Day 3} \\
\hline$\%$ Cleaved embryos ${ }^{3}$ & $82 \pm 2$ & $78 \pm 1$ & $77 \pm 4$ & $73 \pm 3$ & 0.14 \\
\hline$\geq 8$-cell embryos ( $\%$ of oocytes) & $49 \pm 8$ & $51 \pm 4$ & $45 \pm 5$ & $50 \pm 4$ & 0.79 \\
\hline$\geq 8$-cell embryos ( $\%$ of embryos $)^{4}$ & $59 \pm 9$ & $65 \pm 6$ & $58 \pm 5$ & $68 \pm 2$ & 0.59 \\
\hline \multicolumn{6}{|l|}{ Day 7} \\
\hline Blastocysts ( $\%$ of oocytes) & $13 \pm 2$ & $23 \pm 2$ & $20 \pm 3$ & $22 \pm 6$ & 0.07 \\
\hline Blastocysts (\% of embryos) & $16 \pm 3$ & $30 \pm 2$ & $26 \pm 2$ & $29 \pm 7$ & 0.02 \\
\hline \multicolumn{6}{|l|}{ Day 8} \\
\hline$\%$ Blastocysts ( $\%$ of oocytes) & $31 \pm 7$ & $36 \pm 5$ & $31 \pm 3$ & $28 \pm 7$ & 0.99 \\
\hline$\%$ Blastocysts (\% of embryos) & $38 \pm 8$ & $46 \pm 6$ & $40 \pm 3$ & $38 \pm 8$ & 0.69 \\
\hline$\%$ Advanced blastocysts ( $\%$ of oocytes) & $3 \pm 1$ & $10 \pm 3$ & $8 \pm 2$ & $7 \pm 4$ & 0.24 \\
\hline$\%$ Advanced blastocysts ( $\%$ of embryos) & $4 \pm 2$ & $13 \pm 3$ & $11 \pm 2$ & $9 \pm 5$ & 0.22 \\
\hline Blastomere Number & $124 \pm 8$ & $121 \pm 8$ & $129 \pm 10$ & $129 \pm 9$ & 0.96 \\
\hline
\end{tabular}

${ }^{1}$ For embryo development data, $\mathrm{n}=4$ replicate studies; 26 to $35 \mathrm{COCs} /$ replicate. For cell number assessment, $\mathrm{n}=26$ to 34 blastocysts examined over 4 replicate studies; ${ }^{2}$ Represents the P value for themean comparisons; ${ }^{3}$ Based on the percentage of total oocytes; ${ }^{4}$ Based on the percentage of cleaved embryos. 


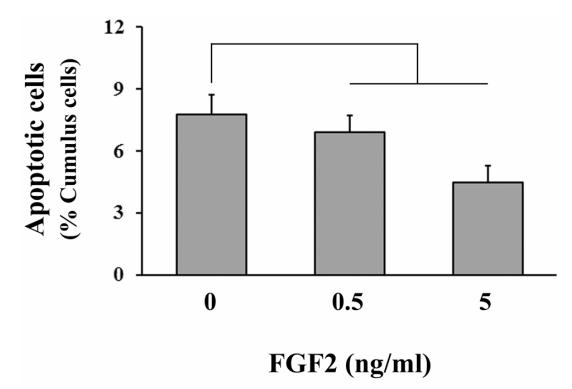

Figure 2. The effect of FGF2 supplementation during IVM on cumulus cell apoptosis. COCs ( $\mathrm{n}=25$ - 35/replicate; 4 replicate studies) were cultured in maturation medium containing FSH and $0,0.5,5$ or $50 \mathrm{ng} / \mathrm{ml}$ FGF2. After $21 \mathrm{~h}, \mathrm{COCs}$ were fixed and processed to determine the percentage of TUNEL-positive cumulus cells in each COC. A significant difference between controls and both FGF2 treatment groups was detected by using orthogonal contrasts $(\mathrm{P}=$ $0.03)$.

apoptosis-related genes was examined in cumulus cells harvested after 6 and $21 \mathrm{~h}$ of maturation. Supplementation with $5 \mathrm{ng} / \mathrm{ml} \mathrm{FGF2}$ did not affect the relative abundance of any apoptosis-related transcripts that were examined at each time-point, which included BCL2, XIAP, $B A X, B A D$ and $F A S$ (data not shown).

A final study was completed to determine if FGF2 supplementation altered the expression of selective cumulus-expressed transcripts associated with oocyte competency $[30,32,34-36]$. Cumulus cells were isolated from COCs cultured in medium containing 0 or $5 \mathrm{ng} / \mathrm{ml} \mathrm{FGF} 2$ for $6 \mathrm{~h}$ or at the completion of IVM. No FGF2-dependent differences in any of the cumulus markers of oocyte competency were detected. Transcripts examined included CTSB, SPRY2, EGFR, FSHR and HAS2 (data not shown).

\section{DISCUSSION}

This work described whether addition of FGF2 during IVM improves subsequent embryogenesis. Bovine IVM/ IVF/IVC procedures produce embryos that usually are inferior at generating viable offspring than in vivo-derived embryos. Pregnancy rates at day 28 - 32 usually are reduced and subsequent pregnancy losses are increased following transfer of IVP-embryos to recipients at day 7 post-estrus [25,37]. The interest in examining FGF2 as an oocyte competency factor was proposed because it is produced by theca, granulosa and cumulus cells throughout follicuologenesis $[21,22]$, transcripts for several FGFR isotypes that bind FGF2 preside in cumulus cells and oocytes [6], and it serves important roles during folliculogenesis [19].

Supplementation with FGF2 during IVM promoted blastocyst formation at day 7 post-IVF. This finding is consistent with recent work examining the role of FGF10 as an oocyte competency factor [6]. However, that study also detected beneficial effects for FGF10 on embryo development at day $3(\% \geq 8$-cell embryos) and day $8(\%$ advanced blastocysts). These effects were not evident following FGF2 supplementation. Perhaps the less pronounced effects of supplemental FGF2 in this work occurred because cumulus cells produce FGF2 but not FGF10 [20-22]. FGF10 is produced primarily by theca cells, which are absent during IVM [7]. Therefore, it seems reasonable to propose that the impact of supplemental FGF2 could have been masked by endogenous sources of FGF2. Alternatively, FGF2 and 10 act through distinct receptor subtypes [38], and perhaps these differences in biological responses are reflective of this differential receptor usage. Regardless of the reason, observing that both FGF2 and 10 increase blastocyst formation at day 7 is interesting since early blastocyst formation in vitro is associated with increased embryo competency after embryo transfer $[39,40]$. This implicates both factors as oocyte competency factors.

It remains unclear how FGF2 supplementation impacts oocyte maturation. Increases in polar body extrusion rates were observed when intact COCs were exposed to FGF2 but subsequent fertilization rates were unaffected by FGF2 treatment. Further investigations are needed to describe how FGF2 mediates the timing of meiosis and how this may impact fertilization success.

The exact mechanism(s) used by FGF2 during IVM to impact subsequent embryo development has not been delineated but cumulus cells likely are mediating at least some of the FGF2 effects. Cumulus cells certainly are needed for FGF2-mediated effects on meiosis. Unfortunately the denuded oocyte maturation model could not be used to examine if cumulus cells mediate FGF2 effects on subsequent fertilization and embryo development. Fertilization and development rates were severely compromised in oocytes denuded prior to IVM (data not shown).Cumulus expansion is a good predictor of oocyte competency for fertilization and subsequent embryo development $[30,41,42]$. However, FGF2 did not affect cumulus expansion and did not affect the relative abundance of transcripts encoding factors that regulate cumulus expansion $(E G F R, F S H R, H A S)[32,34,35]$. FGF2 also did not affect the relative abundance of other cumulus competency markers (CTSB, SPRY2) $[30,36]$ but improved survival rates of cumulus cells. Cumulus cells undergo spontaneous apoptosis during IVM [43] and FGF2 supplementation limited the percentage of TUNELpositive cumulus cells. The mechanism used by FGF2 to elicit this response remains unknown.

In summary, this work supports the concept that selective factors found within the follicular niche can be used 
to improve bovine IVP success. Supplementing FGF2 during IVM improves oocyte maturation and blastocyst formation at day 7 post-IVF. The specific mechanisms utilized by FGF2 to improve oocyte competency to form blastocysts was not uncovered but probably is mediated by modifications in cumulus cell activity and/or viability during IVM.

\section{ACKNOWLEDGEMENTS}

Authors thank William Rembert for his assistance with collecting ovaries and personnel at Central Beef Packing Co. (CenterHill, FL) for their generosity in supplying ovaries for research. Authors also thank Dr. Peter J. Hansen and members of his laboratory for sharing laboratory equipment, space and expertise. Thanks also go to Southeastern Semen Services (Wellborn, FL) for donating bull semen. This project was supported by National Research Initiative Competitive Grant number 2008-35203-19106 from the USDA National Institute of Food and Agriculture.

\section{REFERENCES}

[1] Li, Q., McKenzie, L.J. and Matzuk, M.M. (2008) Revisiting oocyte-somatic cell interactions: In search of novel intrafollicular predictors and regulators of oocyte developmental competence. Molecular Human Reproduction, 14, 673-678. doi:10.1093/molehr/gan064

[2] Binelli, M. and Murphy, B.D. (2010) Coordinated regulation of follicle development by germ and somatic cells. Reproduction, Fertility and Development, 22, 1-12. doi:10.1071/RD09218

[3] Gilchrist, R.B., Lane, M. and Thompson, J.G. (2008) Oocyte-secreted factors: Regulators of cumulus cell function and oocyte quality. Human Reproduction Update, 14, 159-177. doi:10.1093/humupd/dmm040

[4] Hussein, T.S., Thompson, J.G. and Gilchrist, R.B. (2006) Oocyte-secreted factors enhance oocyte developmental competence. Developmental Biology, 296, 514-521. doi:10.1016/j.ydbio.2006.06.026

[5] Yeo, C.X., Gilchrist, R.B., Thompson, J.G. and Lane, M. (2008) Exogenous growth differentiation factor 9 in oocyte maturation media enhances subsequent embryo development and fetal viability in mice. Human Reproduction, 23, 67-73. doi:10.1093/humrep/dem140

[6] Zhang, K., Hansen, P.J. and Ealy, A.D. (2010) Fibroblast growth factor 10 enhances bovine oocyte maturation and developmental competence in vitro. Reproduction, 140, 815-826. doi:10.1530/REP-10-0190

[7] Buratini, J. Jr., Pinto, M.G., Castilho, A.C., Amorim, R.L., Giometti, I.C., Portela, V.M., Nicola, E.S. and Price, C.A. (2007) Expression and function of fibroblast growth factor 10 and its receptor, fibroblast growth factor receptor 2B, in bovine follicles. Biology of Reproduction, 77, 743750. doi:10.1095/biolreprod.107.062273

[8] Berisha, B., Sinowatz, F. and Schams, D. (2004) Expression and localization of fibroblast growth factor (FGF) family members during the final growth of bovine ovar- ian follicles. Molecular Reproduction and Development, 67, 162-171. doi: $10.1002 / \mathrm{mrd} .10386$

[9] Buratini, J. Jr., Teixeira, A.B., Costa, I.B., Glapinski, V.F., Pinto, M.G., Giometti, I.C., Barros, C.M., Cao, M., Nicola, E.S. and Price, C.A. (2005) Expression of fibroblast growth factor- 8 and regulation of cognate receptors, fibroblast growth factor receptor-3c and -4 , in bovine antral follicles. Reproduction, 130, 343-350. doi:10.1530/rep.1.00642

[10] Parrott, J.A. and Skinner, M.K. (1998) Developmental and hormonal regulation of keratinocyte growth factor expression and action in the ovarian follicle. Endocrinology, 139, 228-235. doi:10.1210/en.139.1.228

[11] Schams, D., Steinberg, V., Steffl, M., Meyer, H.H. and Berisha, B. (2009) Expression and possible role of fibroblast growth factor family members in porcine antral follicles during final maturation. Reproduction, 138, 141149. doi:10.1530/REP-09-0033

[12] Sugiura, K., Su, Y.Q., Diaz, F.J., Pangas, S.A., Sharma, S., Wigglesworth, K., O’Brien, M.J., Matzuk, M.M., Shimasaki, S. and Eppig, J.J. (2007) Oocyte-derived BMP15 and FGFs cooperate to promote glycolysis in cumulus cells. Development, 134, 2593-2603. doi:10.1242/dev.006882

[13] Puscheck, E.E., Patel, Y. and Rappolee, D.A. (1997) Fibroblast growth factor receptor (FGFR)-4, but not FGFR3 is expressed in the pregnant ovary. Molecular and Cellular Endocrinology, 132, 169-176. doi:10.1016/S0303-7207(97)00131-7

[14] Valve, E., Penttila, T.L., Paranko, J. and Harkonen, P. (1997) FGF-8 is expressed during specific phases of rodent oocyte and spermatogonium development. Biochemical and Biophysical Research Communications, 232, 173-177. doi:10.1006/bbrc.1997.6256

[15] Ben-Haroush, A., Abir, R., Ao, A., Jin, S., Kessler-Icekson, G., Feldberg, D. and Fisch, B. (2005) Expression of basic fibroblast growth factor and its receptors in human ovarian follicles from adults and fetuses. Fertility and Sterility, 84, 1257-1268. doi:10.1016/j.fertnstert.2005.05.018

[16] Knee, R.S., Pitcher, S.E. and Murphy, P.R. (1994) Basic fibroblast growth factor sense (FGF) and antisense (gfg) RNA transcripts are expressed in unfertilized human oocytes and in differentiated adult tissues. Biochemical and Biophysical Research Communications, 205, 577-583. doi:10.1006/bbrc.1994.2704

[17] Gospodarowicz, D. and Bialecki, H. (1979) Fibroblast and epidermal growth factors are mitogenic agents for cultured granulosa cells of rodent, porcine, and human origin. Endocrinology, 104, 757-764. doi:10.1210/endo-104-3-757

[18] Peluso, J.J. and Pappalardo, A. (1999) Progesterone maintains large rat granulosa cell viability indirectly by stimulating small granulosa cells to synthesize basic fibroblast growth factor. Biology of Reproduction, 60, 290-296. doi:10.1095/biolreprod60.2.290

[19] Nilsson, E., Parrott, J.A. and Skinner, M.K. (2001) Basic fibroblast growth factor induces primordial follicle development and initiates folliculogenesis. Molecular and 
Cellular Endocrinology, 175, 123-130. doi:10.1016/S0303-7207(01)00391-4

[20] Bieser, B., Stojkovic, M., Wolf, E., Meyer, H. and Einspanier, R. (1998) Growth factors and components for extracellular proteolysis are differentially expressed during in vitro maturation of bovine cumulus-oocyte complexes. Biology of Reproduction, 59, 801-806. doi:10.1095/biolreprod59.4.801

[21] Berisha, B., Sinowatz, F. and Schams, D. (2004) Expression and localization of fibroblast growth factor (FGF) family members during the final growth of bovine ovarian follicles. Molecular Reproduction and Development, 67, 162-171. doi:10.1002/mrd.10386

[22] Berisha, B., Steffl, M., Amselgruber, W. and Schams, D. (2006) Changes in fibroblast growth factor 2 and its receptors in bovine follicles before and after GnRH application and after ovulation. Reproduction, 131, 319-329. doi:10.1530/rep. 1.00798

[23] Wang, X., Schutzkus, V., Huang. W., Rosa, G.J. and Khatib, H. (2009) Analysis of segregation distortion and association of the bovine FGF2 with fertilization rate and early embryonic survival. Animal Genetics, 40, 722-728. doi:10.1111/j.1365-2052.2009.01904.x

[24] Rivera, R.M. and Hansen, P.J. (2001) Development of cultured bovine embryos after exposure to high temperatures in the physiological range. Reproduction, 121, 107115. doi:10.1530/rep. 0.1210107

[25] Loureiro, B., Bonilla, L., Block, J., Fear, J.M., Bonilla, A.Q. and Hansen, P.J. (2009) Colony-stimulating factor 2 (CSF-2) improves development and posttransfer survival of bovine embryos produced in vitro. Endocrinology, 150, 5046-5054. doi:10.1210/en.2009-0481

[26] Fields, S.D., Hansen, P.J. and Ealy, A.D. (2011) Fibroblast growth factor requirements for in vitro development of bovine embryos. Theriogenology, 75, 1466-1475. doi:10.1016/j.theriogenology.2010.12.007

[27] Kobayashi, K., Yamashita, S. and Hoshi, H. (1994) Influence of epidermal growth factor and transforming growth factor-alpha on in vitro maturation of cumulus cell-enclosed bovine oocytes in a defined medium. Journal of Reproduction and Fertility, 100, 439-446. doi:10.1530/jrf.0.1000439

[28] Fear, J.M. and Hansen, P.J. (2011) Developmental changes in expression of genes involved in regulation of apoptosis in the bovine preimplantation embryo. Biology of Reproduction, 84, 43-51. doi:10.1095/biolreprod.110.086249

[29] Paula-Lopes, F.F., Boelhauve, M., Habermann. F.A., Sinowatz, F. and Wolf, E. (2007) Leptin promotes meiotic progression and developmental capacity of bovine oocytes via cumulus cell-independent and -dependent mechanisms. Biology of Reproduction, 76, 532-541. doi:10.1095/biolreprod.106.054551

[30] Bettegowda, A., Patel, O.V., Lee, K.B., Park, K.E., Salem, M., Yao, J., Ireland, J.J. and Smith, G.W. (2008) Identification of novel bovine cumulus cell molecular markers predictive of oocyte competence: Functional and diagnostic implications. Biology of Reproduction, 79, 301-309. doi:10.1095/biolreprod.107.067223
[31] Ireland, J.J., Zielak-Steciwko, A.E., Jimenez-Krassel, F., Folger, J., Bettegowda, A., Scheetz, D., Walsh, S., Mossa, F., Knight, P.G., Smith, G.W., et al. (2009) Variation in the ovarian reserve is linked to alterations in intrafollicular estradiol production and ovarian biomarkers of follicular differentiation and oocyte quality in cattle. Biology of Reproduction, 80, 954-964.

doi:10.1095/biolreprod.108.073791

[32] Assidi, M., Dufort, I., Ali, A., Hamel, M., Algriany, O., Dielemann, S. and Sirard, M.A. (2008) Identification of potential markers of oocyte competence expressed in bovine cumulus cells matured with follicle-stimulating hormone and/or phorbol myristate acetate in vitro. Biology of Reproduction, 79, 209-222. doi:10.1095/biolreprod.108.067686

[33] SAS Institute Inc., Cary, USA.

[34] Caixeta, E.S., Ripamonte, P., Franco, M.M., Junior, J.B. and Dode, M.A. (2009) Effect of follicle size on mRNA expression in cumulus cells and oocytes of Bos indicus: An approach to identify marker genes for developmental competence. Reproduction, Fertility and Development, 21, 655-664. doi:10.1071/RD08201

[35] Dragovic, R.A., Ritter, L.J., Schulz, S.J., Amato, F., Armstrong, D.T. and Gilchrist, R.B. (2005) Role of oocytesecreted growth differentiation factor 9 in the regulation of mouse cumulus expansion. Endocrinology, 146, 27982806. doi:10.1210/en.2005-0098

[36] Sugiura, K., Su, Y.Q., Li, Q., Wigglesworth, K., Matzuk, M.M. and Eppig, J.J. (2009) Fibroblast growth factors and epidermal growth factor cooperate with oocyte-derived members of the TGFbeta superfamily to regulate Spry 2 mRNA levels in mouse cumulus cells. Biology of Reproduction, 81, 833-841. doi:10.1095/biolreprod.109.078485

[37] Block, J., Drost, M., Monson, R.L., Rutledge, J.J., Rivera, R.M., Paula-Lopes, F.F., Ocon, O.M., Krininger, C.E., 3rd, Liu, J. and Hansen, P.J. (2003) Use of insulin-like growth factor-I during embryo culture and treatment of recipients with gonadotropin-releasing hormone to increase pregnancy rates following the transfer of in vitro-produced embryos to heat-stressed, lactating cows. Journal of Animal Science, 81, 1590-1602.

[38] Ornitz, D.M. (2000) FGFs, heparan sulfate and FGFRs: Complex interactions essential for development. BioEssays, 22, 108-112.

doi:10.1002/(SICI)1521-1878(200002)22:2<108::AID-BI ES2>3.0.CO;2-M

[39] Hasler, J.F., Henderson, W.B., Hurtega, P.J., Jin, Z.Q., McCauley, A.D. and Mower, S.A. (1995) Production, freezing and transfer of bovine IVF embryos and subsequent calving results. Theriogenology, 43, 141-152. doi:10.1016/0093-691X(94)00020-U

[40] Kubisch, H.M., Sirisathien, S., Bosch, P., Hernandez-Fonseca, H.J., Clements, G., Liukkonen, J.R. and Brackett, B.G. (2004) Effects of developmental stage, embryonic interferon-tau secretion and recipient synchrony on pregnancy rate after transfer of in vitro produced bovine blastocysts. Reproduction in Domestic Animals, 39, 120-124. doi:10.1111/j.1439-0531.2004.00491.x 
[41] Anderson, R.A., Sciorio, R., Kinnell, H., Bayne, R.A., Thong, K.J., De Sousa, P.A. and Pickering, S. (2009) Cumulus gene expression as a predictor of human oocyte fertilisation, embryo development and competence to establish a pregnancy. Reproduction, 138, 629-637.

doi:10.1530/REP-09-0144

[42] Lonergan, P., Carolan, C., Van Langendonckt, A., Donnay, I., Khatir, H. and Mermillod, P. (1996) Role of epidermal growth factor in bovine oocyte maturation and preimplantation embryo development in vitro. Biology of Reproduction, 54, 1420-1429. doi:10.1095/biolreprod54.6.1420

[43] Ikeda, S., Imai, H. and Yamada, M. (2003) Apoptosis in cumulus cells during in vitro maturation of bovine cumulus-enclosed oocytes. Reproduction, 125, 369-376. doi: $10.1530 /$ rep. 0.1250369 